British Journal of Psychiatry (1995), 166, 676-681

\title{
Correspondence
}

Contents: British Doctors and Dentists Group/ Psychological debriefing/Charles Bonnet syndrome/ The nature of dysthymia/Where shall we put lithium et al?/Lithium augmentation/Hypomania induced by gabapentin/Schizophreniform psychosis after stage hypnosis/Nietzche, Freud and eternal recurrence of the repressed ...

\section{British Doctors and Dentists Group}

SIR: I am a member of the British Doctors and Dentists Group that Brook (BJP, February 1995, 166, 149-153) mentions, and wish to inform colleagues of the activities of that group.

The B.D.D.G. started 20 years ago in London. From an initial single meeting in London at that time we have now grown to 14 groups spread throughout England, Wales, Northern Ireland and a group in Dublin. Membership consists of doctors and dentists in recovery from chemical dependency and alcoholism. Groups meet on a regular basis in confidential surroundings to share experiences and to provide support for each other.

For some years our dental colleagues in the B.D.D.G. have successfully run a scheme to allow them to intervene and assist a sick dentist in response to a request from that dentist or a spouse or partner. That scheme has been supported by a locum scheme and access to funding for treatment facilities. We doctors are now, in response to growing concern about the welfare and consequences of addicted doctors, looking at the ways in which we can respond.

We have a national committee which is looking at the organisation and provision of assistance for addicted doctors. We have a network of doctors, themselves established in recovery from addictive illnesses, who are willing and able to respond to and assist a suffering colleague. This network may be accessed via the Medical Council on Alcoholism (as described by Brook) or directly on 01252-316976 via Dr Ian Joyner. We are happy to receive requests for advice or assistance from doctors who are concerned that they have or may have an addiction problem or from their spouses or partners. We promise absolute confidentiality. (In order to avoid conflict of loyalties it would be our practice to avoid putting an enquirer in direct contact with somebody who might be an immediate colleague of a sick doctor.) Through the local groups we may be able to offer advice regarding specific treatment opportunities as well as advice on obtaining funding. We also have a families network whereby it is possible for us to put the spouse of an addicted doctor in contact with other spouses in order to provide support and advice in that way.

As an organisation we have no official links or obligations to the G.M.C. or any other statutory or regulating body. We have over the years, however, enjoyed a good relationship with the G.M.C. and have worked successfully with them in assisting individuals who had already been brought to their attention.

\section{Knowle Hospital \\ Fareham}

Hants PO17 3NA

\section{Psychological debriefing}

SIR: Bisson \& Deahl (BJP, December 1994, 165, 717-720) question whether empirical evidence exists to justify use of psychological debriefing (PD) in the prevention of post-traumatic stress disorder (PTSD).

PD was described by Dyregov (1989) but is only one of four similar techniques incorporated under the term 'critical incident stress debriefing' originally described by Mitchell (1983). Studies tend not to distinguish which technique is being evaluated.

PD was devised for groups of emergency workers and recommended for use within $\mathbf{4 8}$ hours of traumatisation. Recently, PD has been applied to individuals as opposed to groups and used with primary not secondary victims. It has also been used as a treatment measure, not just in prevention. Conclusions about the efficacy of the technique cannot be made without addressing differences in application.

PD allows individuals meeting in a structured group format, who have been exposed to the same 